\title{
A VIDA ESCRITA EM BYTES. A SOCIEDADE SUPERINFORMACIONAL E AS NOVAS TECNOLOGIAS: SERÁ O FIM DA PRIVACIDADE E DA DIGNIDADE HUMANA?
}

\author{
LIFE WRITTEN IN BYTES . THE SUPERINFORMACIONAL AND NEW \\ TECHNOLOGIES COMPANY : WILL THE END OF PRIVACY AND HUMAN \\ DIGNITY ?
}

${ }^{1}$ Cleide Aparecida Gomes Rodrigues Fermentão

${ }^{2}$ Ricardo da Silveira e Silva

\section{RESUMO}

As recentes tecnologias alteraram a forma de comunicação social do ser humano, que passa a estabelecer contato direto com diversas pessoas em qualquer lugar do mundo. Aliado a esse fato, tem-se uma virtualização cada vez maior da pessoa humana, culminando em uma imersão no mundo virtual, que acaba por criar uma dependência cada vez maior da tecnologia para poder existir socialmente. Essa transformação no mundo dos conceitos faz com que o virtual passe a ter repercussão direta no mundo real. Atraído pelo brilho e o fascínio da rede virtual, a pessoa não encontra limites para a sua autopromoção. A vida privada é cada vez mais exposta para um número indeterminado de pessoas. Assim, a pessoa que se expõe nos meios virtuais em busca de aceitação, esquece-se que não está somente se desnudando de suas vestes ou de sua intimidade, mas, principalmente, está se despindo de sua dignidade. A busca desenfreada por algumas curtidas não encontra limite no bom senso, coisificando a pessoa e transformando-a em mero perfil virtual. A pessoa humana encontra, neste estado, a total falta de dignidade, sem que se perceba, torna-se um objeto em exposição. A internet é um palco propício para a espetacularização do eu virtual, o que faz dela um campo fértil para a indignidade. A história da civilização remonta a luta e a conquista da dignidade da pessoa humana, todavia, a época em que se vive assiste um movimento inverso. Contemporaneamente não é mais o estado ou o particular a constituir ameaça constante a dignidade humana. Aqueles que, seduzidos pela possibilidade de se tornarem a personalidade do momento, voluntariamente abdicam da sua dignidade em um processo cuja reversibilidade é questionável. A legislação não consegue acompanhar a velocidade das transformações ocorridas no mundo virtual e esse descompasso pode deixar a pessoa desprotegida principalmente em relação aos seus direitos à intimidade, privacidade e a própria dignidade humana.

Palavras-chave: Dignidade da pessoa humana, Exposição, Ambiente virtual

1Doutora em Direito pela Universidade Federal do Paraná - UFPR, Curitiba (Brasil). Proprietária - Escritório de Advocacia Cleide Fermentão e professora titular do Centro Universitário de Maringá - CEUMAR, Paraná. Email: cleidefermentao@gmail.com

${ }^{2}$ Mestre em Ciências Jurídicas pelo Centro de Ensino Superior de Maringá - CESUMAR, Paraná, (Brasil). Professor de Graduação e Pós Graduação na Faculdade Metropolitana de Maringá - FAMMA e CEUMAR em Maringá, Paraná. E-mail: stone_man@uol.com.br 


\begin{abstract}
Recent technologies have changed the way media of the human being, which shall establish direct contact with many people anywhere in the world. Allied to this fact, there is a virtualization increasing the human person, culminating in an immersion in the virtual world, which ultimately creates an increasing dependence on technology in order to exist socially. This transformation in the world of concepts makes the virtual pass to have direct impact in the real world. Attracted by the glitter and glamor of virtual network, the person finds no limits to their self-promotion. The private life is increasingly exposed to an undetermined number of people. So the person who is exposed in the virtual media in search of acceptance, forgets that it is not only stripping of his clothes or his privacy, but mainly is stripped of his dignity. The frantic search for some "tanned" finds no limit on common sense, coisificando the person and transforming it into mere virtual profile. The human person is in this state, the total lack of dignity, without realizing it, it becomes an object on display. The internet is a stage conducive to the spectacle of the self virtual, making it fertile ground for the indignity. The history of civilization dating back to fighting and winning the dignity of the human person, however, the time in which we live watch a reverse movement. Contemporaneously it is no longer the state or private to be constant threat to human dignity. Those who, seduced by the possibility of becoming the personality of the time, voluntarily abdicate their dignity in a process whose reversibility is questionable. The legislation can not keep up the speed of the transformations occurred in the virtual world and this mismatch can leave unprotected person especially in relation to their rights to intimacy, privacy and human dignity itself.
\end{abstract}

Keywords/Palabras-claves/Mots-clés: Human dignity, Exhibition, Virtual environment 


\section{INTRODUÇÃO}

O uso da internet e sua crescente democratização, aumenta, em alcance e em número de usuários, em ritmo exponencial, conectando as pessoas por intermédio de computadores, tablets e telefones celulares, contribuindo para a construção de novos paradigmas de comunicação, imprimindo maior dinamicidade às interações pessoais, com a criação de redes sociais e novas formas de comunicação pessoal, tornando extremamente fácil e rápida o diálogo e a disseminação de informações. No entanto, paralelo a este quadro de otimismo, o surgimento de novas tecnologias para internet acabam por relativizar o direito a intimidade $\mathrm{e}$ à privacidade no âmbito virtual.

Ao mesmo tempo em que se pode manter contatos familiares, sociais e profissionais espalhados pelo mundo todo, necessita-se cada vez mais da tecnologia como mediadora do relacionamento entre as pessoas, arrastando o convívio social para o mundo virtual e criando, com isso, uma infinidade de dados que transitam pela internet sem qualquer tipo de controle.

Se antes a exposição dependia de ato próprio e positivo da pessoa humana para acontecer, com a postagem de imagem ou fato pessoal na internet, hoje uma simples pesquisa na internet basta para que ela se depare com um sem número de propagandas acerca do objeto pesquisado, em diversos outros sites, denunciando a existência de captação de conteúdo virtual para a formação de bancos de dados sem qualquer tipo de autorização, o que viola aspectos inerentes à personalidade humana e o mais elementar direito à intimidade e privacidade.

Há uma grande variedade de redes sociais com milhões de pessoas, com aplicativos de entretenimento dos mais diversificados estilos e gostos, com agendas para eventos e aniversários e interação muito prática e simples entre os usuários, sendo que toda essa facilidade atrai cada vez mais pessoas que se integram a essas redes sem o devido cuidado sobre as informações que estão transmitindo. Usuários postam fotos, contam de suas vidas, informam lugares que frequentam, onde trabalham, a faculdade ou colégio que estudam, quando e para onde viajam, tudo é facilmente descoberto com um clique.

O risco ao qual as pessoas se submetem ao divulgar suas informações pessoais, seus gostos, vontades e pensamentos é imensurável, sem esquecer de que mensagens, fotos, e todas as informações que são postadas podem se perpetuar em algumas redes sociais, já que os sites podem salvar tais dados em seu sistema, sob a justificava de que o usuário pode querer reabrir a conta, tendo sobre elas total direito de uso, ou ainda, sob o pretexto de que tal coleta de informações servirá para aperfeiçoar a experiência do internauta no uso da rede virtual. Diante 
de tais afirmações, é possível dizer que o resultado destes fatos é que o respeito à privacidade como direito personalíssimo apresenta-se como uma exigência cada vez mais urgente. Assim, O Direito à privacidade e à dignidade humana encontram-se fragilizados diante da exposição pública pelo avanço tecnológico e da necessidade de autopromoção no mundo virtual?

No presente trabalho foi empregado o método teórico compilativo, em especial a análise bibliográfica, cujo escopo é estudo das novas tecnologias como instrumento facilitador as afrontas cometidas contra a dignidade da pessoa humana.

\section{INTERNET: O PARAÍSO DIGITAL}

A internet é um paraíso digital (LANIER, 2012, p. 18). Pela primeira vez a humanidade não tem apenas um mas muitos mundos para viver. (CASTRONOVA, 2005, p. 44) A internet proporcionou uma experiência de liberdade até então desconhecida pelo ser humano, que tinha nos limites físicos um grande obstáculo para comunicação, informação e interação social. Se antes era necessário ir ao encontro de alguém para ter a sua companhia, agora bastar estar conectado a uma mesma plataforma para efetuar contato online com quem quer que seja e onde quer que esteja.

O virtual é um mundo brilhante, reluzente e chamativo. Nele é possível até mesmo uma existência diferente daquela real, pois as possibilidades e formas de acesso são inúmeras, sendo viável o trânsito apenas por lugares prazerosos. Ao ingressar nesse espectro, experimenta-se possibilidades que vão além daquelas do mundo físico. A rede virtual apresenta espaços atrativos e interessantes, que funcionam como verdadeiros cenários para o desenvolvimento de ideias e relacionamentos. São espaços que possuem os mais diversos recursos interativos, facilitando a navegação pelas informações arquivadas, além da oportunidade do anonimato, que dá uma sensação de liberdade inexistente no mundo físico.

Nesse espaço é possível buscar somente aquilo que lhe convém, transitando pelos mundos escolhidos previamente, de forma a fazer real o seu mundo ideal (LEVY, 2011, p. 40). Tal fato, aliado a privatização dos espaços públicos, torna o mundo virtual extremamente atraente, onde as possibilidades criativas encontram menos amarras, inclusive as sociais.

A internet propicia a comunicação desinibida, uma vez que favorece o anonimato e desta forma se consolida como ferramenta de fortalecimento de expressão e comunicação. O anonimato induz a liberação, sem constrangimentos de emoções aprisionadas, em especial concede ao indivíduo a possibilidade de expor sua vida sem revelar sua real identidade. Assim, 
o anonimato que protege os usuários da internet serve a construção de uma sociedade pluralista, fundada na democracia (VIEIRA, 2007, p. 198).

A forma de utilizar e desfrutar da internet pode variar de sociedade, as preferências dos usuários por determinados serviços não variam de acordo com o custo, mas sim sofrem influencias culturais e sociais de cada sociedade (LAGARES, P. 70), ou seja, a facilidade de acesso e o baixo custo concede extraordinária acessibilidade a rede, sendo que a sua utilização curva-se aos interesses individuais e culturais de cada indivíduo.

A rede também consiste em um campo fértil para que ocorram afrontas a dignidade da pessoa, uma vez que o anonimato dificulta a apuração de ilícitos praticados no mundo virtual como a violação a intimidade, privacidade, honra, imagem do indivíduo, bem como facilita a comunicação entre terroristas e membros de organizações criminosas que se escondem sob o manto do sigilo ofertado pela internet (VIEIRA, 2007, p. 199). É inegável o avanço ocorrido com o advento da internet, apresentando-se como uma maravilha a disposição de todos, e capaz de transpor as barreiras físicas do espaço e a limitação temporal. Ocorre que, o paraíso repleto de facilidades e possibilidades pode ser utilizado de tal forma a ferir a pessoa humana atentando contra sua dignidade, atingindo inclusive a sua segurança real e sua sanidade mental.

\section{O SHOW DO EU: A VIDA PRIVADA ENCENADA}

Afinal, qual o valor de uma curtida em uma rede social? Por que a vida privada e íntima da pessoa tornou-se um espetáculo encenado para milhares? A sociedade atual vivencia novas formas de pensar, viver, sentir (SIBILIA, 2008, p. 11), enfim, os novos modos de ser e as novas tecnologias da informação auxiliam as pessoas a se aproximarem dos assuntos de seu interesse. E é justamente nesse universo on-line que tem-se notado o surgimento de novas formas de exposição pública, com o comprometimento cada vez maior da intimidade e privacidade pessoal, na busca incessante de popularidade, fama e glória. É o desejo de se tornar celebridade levado à condição de fetiche pessoal (LUDLOW, 2010, p. 275), utilizando-se de uma rede que confere um grande poder de divulgação, ao mesmo tempo que isenta o usuário da responsabilidade pelo material que divulga. (ARANGY, 2011, p. 38)

O ser humano possui verdadeiro fascínio pela fama, mesmo que momentânea. Os atuais programas televisivos onde os protagonistas são pessoas comuns, como no caso dos reality shows, possuem um forte apelo popular e atraem a atenção de um volumoso segmento da sociedade, que também almeja estar ocupando aquele espaço, com o qual sairão coroados com a popularidade instantânea. O acesso a tais programas é extremamente dificultoso, sobrando 
poucas vagas para uma imensidão de pessoas, que vislumbram nas plataformas virtuais a oportunidade de se tornarem celebridades como aquelas que se constituem o objeto de sua idolatria. A questão é que para aumentar a audiência é comum recorrer a publicações em que se utilizam da exposição da própria intimidade e privacidade como chamariz para desconhecidos. Esse fenômeno já foi identificado e é retratado, com absoluta lucidez, pela autora Paula Sibilia, (2008, p. 31) que aponta a existência de "verdadeiro festival de "vidas privadas", que se oferecem despudoradamente aos olhares do mundo inteiro".

Assiste-se à criação de blogs de notícias e de fotos, além de verdadeiros diários virtuais, onde são expostos regularmente os mais diversos episódios pessoais, em verdadeira narrativa da vida pessoal, com detalhes por vezes constrangedores e picantes da própria realidade, mesmo que seja devidamente aumentada para parecer mais interessante aos olhos alheios, estimulando e aguçando a curiosidade de outrem, afim de atrair maior atenção e popularidade. Isso é parte do processo de convencer os demais de que não se é uma pessoa comum. De que existe algo de especial a tornar diferente aquele que narra a sua vida real no ambiente virtual, fazendo da virtualidade a sua realidade (CASTELLS, 1999, p. 458), com o alargamento dos limites do que se pode dizer e mostrar, exacerbando a esfera da intimidade sob a luz da visibilidade virtual.

Para Paula Sibilia (2008, p. 111) a fama é medida pelas curtidas recebidas, que servem como termômetro para expressar a popularidade angariada com a publicação de fotos ou dados biográficos, sem nenhuma preocupação acerca da própria privacidade e onde o objetivo é tão somente conquistar a visibilidade, e ensina:

Nesta cultura das aparências, do espetáculo e da visibilidade, já não parece haver motivos para mergulhar naquelas sondagens em busca dos sentidos abissais perdidos dentro de si mesmo. Em lugar disso, tendências exibicionistas e performáticas alimentam a procura de um efeito: o reconhecimento nos olhos alheios e, sobretudo, o cobiçado troféu de ser visto.

Nas redes sociais, o mais comum é verificar pessoas que postam até irracionalmente, as direções físicas ou coordenadas dos lugares em que se encontram ou para onde estão se dirigindo, compartilhando fotos suas, de seus familiares e amigos, revelando informações sobre as suas atividades, externando lugares onde os parentes mais próximos costumam frequentar, compartilhando vídeos ou fotos em situações intimas, de modo que todos possam conhecer os aspectos mais íntimos de sua privacidade (LEANDRY-VEJA, 2014, p. 25).

Com efeito, na sociedade informacional os próprios titulares dos dados pessoais conscientemente os disponibilizam para a abertura das contas que lhes permitirão o acesso aos 
serviços de Internet e, a partir daí, passam a expor inúmeras informações. A vulnerabilidade ocorre de maneira imediata, pois basta acessar um site de rede social (como o Facebook) para que os dados pessoais do internauta tais como escolaridade, estado civil, localidade onde reside e muitos outros dados sejam facilmente visualizados e compartilhados por seus contatos e até mesmo por terceiros, sequer conhecidos do internauta. Outra situação recorrente ocorre quando algum contato da rede social faz uma postagem e nela publica imagens, comentários e informações sobre algum amigo, também integrante da mesma rede, que vê alguns de seus dados divulgados sem sua autorização.

Um grande problema em relação a questão de privacidade deve-se ao fato de que as redes sociais online não alertam os usuários sobre os riscos que eles podem estar expostos ao participar da rede, divulgando informações pessoais. Tais redes permitem ao usuário um "limitado" controle sobre a privacidade de suas informações. Em geral, esse controle restringese à quem pode ter acesso e ao que ter acesso no perfil do usuário. Os controles mais comuns relacionam-se à informações do perfil do usuário, informações disponíveis pelos aplicativos instalados e informações sobre as atualizações do usuário. Algumas redes sociais permitem ainda que o usuário controle quem pode encontrá-lo através de buscas e quais informações do perfil podem ser vistas.

O Facebook, rede social mais utilizada no momento, permite um controle mais detalhado das configurações de privacidade, entretanto, muitos entendem que sua interface é muito complexa para os usuários comuns. As ferramentas oferecidas por estes sites para proporcionar privacidade aos dados do usuário não são suficientes para assegurar tal direito. Entretanto, podem criar um sentimento de confiança no usuário que, por essa razão, passará a acreditar que links vindos de pessoas na sua rede não oferecem perigo e se sentirá mais confortável para expor detalhes sobre sua vida na rede, criando a cultura da virtualidade real. (CASTELLS, 1999, p. 462)

Outro aspecto fundamental a levar em conta é que a rede social online é, basicamente, um intermediário. É um mediador entre emitente e destinatário de uma determinada mensagem. Sua existência se justifica, por um lado, pelas vantagens que podem trazer aos seus usuários em termos de proporcionar-lhes uma interação social com características e dinâmica próprias e, por outro, pelas vantagens que o acúmulo de informações pessoais sobre os usuários podem trazer ao proprietário desta rede.

A indução ao fornecimento dos próprios dados pessoais é constante no relacionamento da rede social online com seus usuários, e o modo com que este convite ao compartilhamento é realizado pode ser relevante para que se verifique se há, efetivamente, vontade livre e 
informada quanto aos efeitos deste compartilhamento no momento em que os dados pessoais são fornecidos. O compartilhamento de informações pessoais é da própria natureza da atividade social e também é parte estrutural das redes sociais online. Nas interações sociais tradicionais, dispomos de mecanismos culturais, desenvolvidos com o tempo e profundamente arraigados em nossa cultura que nos proporcionam uma ideia razoável das expectativas que podemos nutrir sobre o que será feito com a informação que revelamos a alguém ou difundimos de forma mais ampla (DONEDA, 2015, p. 6).

A mera existência deste intermediário como entidade autônoma na comunicação pode ser oposta à grande parte dos usuários das redes sociais, cuja motivação para a interação não costuma provir da rede em si, porém das pessoas - seus conhecidos e relacionamentos, que também são usuários da rede. Mas o ponto é que, em última análise, este intermediário - e não as partes da comunicação em si - tem o poder de determinar o tratamento a ser dado às informações pessoais que as partes compartilham.

As expectativas sobre como serão tratadas as informações pessoais dependem diretamente deste intermediário, do gestor da rede social. Suas ações podem determinar, por exemplo, o compartilhamento destas informações com terceiros; a exposição destas informações em perfis públicos ou semirrestritos; a sua utilização para a categorização do usuário dentro de um determinado perfil de comportamento e tantas outras modalidades de tratamento possíveis que não raro extrapolam as possibilidades de tratamento de informações pessoais compartilhadas nas interações sociais tradicionais.

Outra delicada situação enfrentada nas redes sociais refere-se à saída de um usuário de uma determinada rede. É necessário, como garantia do controle de cada usuário sobre os próprios dados pessoais e da sua exposição em uma rede social, que exista a possibilidade do completo cancelamento de todas as informações pessoais pertinentes a este usuário dos arquivos da rede. Este cancelamento, mais do que uma elaboração pontual de um "direito ao esquecimento", refere-se diretamente a um ato de liberdade e do exercício dos poderes atinentes ao consentimento sobre a exposição dos próprios dados (LUDLOW, 2010, P. 137).

Ao obter os dados pessoais de seus usuários mediante expresso consentimento, não ocorre propriamente a transferência dos direitos de disposição sobre tais dados do usuário para a rede social, pois estes, por serem dados pessoais, continuam sendo uma expressão direta da pessoa do usuário e continuam a manter com ele uma relação direta e inafastável. Dessa forma, é dever da rede social reconhecer este caráter dos dados pessoais e fornecer aos seus usuários instrumentos que efetivamente realizem o cancelamento completo dos dados pessoais que lhes foram fornecidos por seus usuários. Assim, não há dúvidas que as redes sociais, embora tenham 
passado a fazer parte da vida diária das pessoas, apresentando inúmeros benefícios, trouxeram uma nova vulnerabilidade a esses usuários que consiste na escassa possibilidade destes conhecerem os efeitos do compartilhamento de suas informações fornecidas ao site de relacionamento e aos supostos "amigos" (LUDLOW, 2010, P. 293).

Além disso, por se tratar de tecnologia recentemente incorporada na vida das pessoas, muitas vezes o titular não percebe o grau de risco a que se expõe diante de determinados usos que faz das tecnologias da informação, especialmente quando divulga dados pessoais sensíveis. Revela-se, portanto, a necessidade de também acolher e considerar juridicamente os dados pessoais como uma nova categoria de direito fundamental, categoria esta que emerge com o intuito de ampliar a proteção dos usuários, tendo como escopo a proteção da dignidade de pessoa humana.

O homem da atualidade tem desperdiçado um direito construído historicamente, ao flexibilizar sua intimidade e privacidade em troca do aplauso virtual. Ao optar por tal caminho o indivíduo acaba por se desconstruir, coisificando sua própria existência.

\section{DIGNIDADE DA PESSOA HUMANA. HÁ DIGNIDADE NA EXISTÊNCIA VIRTUAL?}

Segundo Elymar Szaniawski (2005, P. 140), dignidade da pessoa humana "é um atributo da pessoa humana, que sob o enfoque jurídico é o núcleo essencial dos direitos humanos, tratando-se do fundamento primeiro e da finalidade última do exercício do Estado, bem como dos particulares". A dignidade da pessoa humana é uma conquista galgada ao longo dos tempos, que busca, em última análise, a proteção do indivíduo contra os mais diversos ataques independentemente da origem.

Após inúmeras crises e guerras vividas ao longo dos tempos, surgiu a necessidade de proteger a pessoa de todas as afrontas e barbáries cometidas. Esse anseio surgiu no seio da sociedade, que não mais suportava as mais diversas crueldades cometidas contra o indivíduo. Em especial, o massacre cometido contra os judeus na Segunda Guerra Mundial foi um fato determinante para que fossem garantidos os direitos mais íntimos da pessoa humana, pelo simples fato de ser pessoa, uma vez que a dignidade nasce consigo.

Para Clayton Reis e Wanderson Lago Vaz

O fato de o princípio da dignidade da pessoa representar uma conquista do homem torna-se ainda mais preciosa e mais merecedora de proteção do que se tivesse sido outorgada por uma razão divina ou natural. Exatamente por derivar de um momento histórico, de conjuturas jurídicas, políticas, filosóficas, 
culturais, econômicas e sociais localizadas e reais, é que o princípio da dignidade da pessoa humana ganha enorme valor para nossa análise. (VAZ; REIS, 2007, p. 190)

Para Edilsom Pereira de Farias (2000, p. 60), “a característica fundamental do princípio jurídico da dignidade da pessoa humana que o sobreleva em importância e significado é que ele assegura um minimum de respeito ao homem só pelo fato de ser homem, uma vez que todos os homens são dotados de natureza de igual dignidade $\{\ldots\} "$ ".

Segundo Luiz Antônio Rizzatto Nunes (2002, p. 49), “a dignidade nasce com a pessoa. É-lhe inata. Inerente à sua essência.” Porém, como nenhum indivíduo vive isoladamente, ou seja, a pessoa humana é um ser social, há que se respeitar não somente seus atributos físicos, mas também devem ser tuteladas suas liberdades, para que ele possa se construir e desenvolver, acrescendo dignidade a sua existência.

Ao reconhecer a necessidade de garantir não só a existência da pessoa humana, mas atentar para o fato de que trata-se de um indivíduo multifacetado e dotado de várias potencialidades que podem e devem ser desenvolvidas, a dignidade deixa de ter o caráter de proteção a vida e integridade física e passa a proteger a existência da pessoa humana sob todas as nuances, propiciando sua própria construção (NUNES, 2006, p. 49). Tarefa esta inesgotável e que deve ser perseguida até o fim da vida.

Para Gilberto Haddad Jabur (2000, p. 253) toda pessoa possui dados e informações sobre si que não pretende publicitar, independentemente de motivação, "uma vez que, alijar-se do mundo pode significar o cultivo e o aperfeiçoamento das virtudes". Nota-se que esse pensamento moderno contraria entendimento tido na antiguidade, onde a vida transcorria em espaços públicos e onde não havia preocupação com a intimidade e a privacidade (FARIAS, 2000, p. 253). Todavia, atualmente, essa tarefa se toda cada vez mais difícil de ser atingida em razão do surgimento das novas tecnologias, que vão dissolvendo a capacidade de isolamento do indivíduo.

Nas lições de Gilberto Haddad Jabur (2000, p. 253), garantir o direito à privacidade e à intimidade da pessoa humana é de grande importância, uma vez que, é na intimidade que o indivíduo se constrói. “ $\{\ldots\}$ A soledade é ingrediente para o desenvolvimento sadio da personalidade, de seus valores físicos e psíquicos. $\{\ldots\}$ ”. Assim, o direito ao respeito a vida privada funda-se no direito que cada indivíduo tem de assegurar a paz, a tranquilidade de uma parte de sua vida que não se encontra exposta a apreciação dos demais (ELIMAR, 2005, P. 291). 
O fato é que delimitar o que faz parte da vida privada de uma pessoa é uma tarefa que sofre influência direta da sociedade em que ele está inserido, eis que a ideia de privacidade pode variar de uma sociedade para outra. Assim, não há uma definição estática, pronta e imutável, posto que sofre e sofrerá mutações ao longo dos tempos. O que é inegável é a necessidade de proteção ao isolamento da pessoa humana, por se tratar de uma forma de respeitar a dignidade inerente a cada indivíduo.

Habitualmente utiliza-se a expressão vida privada como sinônimo de privacidade e intimidade, todavia, para o direito tais esferas não se equivalem, uma vez que a privacidade seria o gênero do qual pertencem o direito à intimidade e o direito ao segredo. Imperioso se faz distinguir as duas definições que, no uso cotidiano, muitas vezes são apresentadas como sinônimas, o que acarretaria no fato de terem um conteúdo praticamente equivalente, mas que na realidade possuem definições e extensões diversas.

Fundamental destacar que tanto intimidade quanto privacidade encontram-se intimamente ligados ao princípio da dignidade da pessoa humana, cuja definição, segundo Ingo Wolfgang Sarlet (2001, p. 60) é:

a qualidade intrínseca e distintiva de cada ser humano que o faz merecedor do mesmo respeito e consideração por parte do Estado e da comunidade, implicando, neste sentido, um complexo de direitos e deveres fundamentais que assegurem a pessoa tanto contra todo e qualquer ato de cunho degradante e desumano, como venham a lhe garantir as condições existenciais mínimas para uma vida saudável, além de propiciar e promover sua participação ativa e corresponsável nos destinos da própria existência e da vida em comunhão com os demais seres humanos.

A tarefa de encontrar uma conceituação unívoca e abrangente em razão da enorme gama de aspectos que envolvem o próprio conceito é de extrema complexidade (TOMASZEWSKI, 2006. p. 135). Segundo José Adércio Leite Sampaio (1998, p. 254), para se entender a diferença entre direito à vida privada e direito à intimidade necessário se faz revisitar a chamada "teoria das esferas" que "se funda no fato de que a sociabilidade da pessoa deve servir de limitação à sua liberdade individual, devendo a intensidade da tutela jurídica da personalidade ser inversamente proporcional à sociabilidade do seu comportamento em questão".

A teoria das esferas apresenta camadas ou esferas da personalidade da pessoa humana que carecem de proteção em maior ou menor grau de acordo com que caminha do centro para a periferia. Assim, a camada mais interna, chamada de intimidade ou segredo refere-se ao âmbito mais íntimo do indivíduo, ou seja, não há interação do seu ser ou de seu comportamento com as demais pessoas. Não afeta, portanto, a vida da sociedade, eis que engloba situações 
restritas à própria pessoa, de reserva absoluta, inerente ao conhecimento e consciências individuais. Já a esfera da vida privada é constituída por grupos sociais delimitados cujo indivíduo participe, mas, que seus atos e práticas somente interessem aos grupos não a todos os membros da sociedade. Por fim, há a esfera social ou pública que traduzem a expressão social da pessoa humana, cuja exposição é feita de forma voluntária (SAMPAIO, 1998, p. 255-257), na qual se desenvolve a personalidade da pessoa.

Tércio Sampaio Ferraz Júnior (2011, p. 79), entende que há graus diferentes de exclusividade entre intimidade e vida privada, conforme se depreende do seguinte trecho:

\begin{abstract}
A intimidade é o âmbito do exclusivo que alguém reserva para si, sem nenhuma repercussão social, nem mesmo ao alcance de sua vida privada que, por mais isolada que seja, é sempre um viver entre os outros (na família no trabalho, no lazer em comum). Já a vida privada envolve a proteção de formas exclusivas de convivência. Trata-se de situações em que a comunicação é inevitável (em termos de alguém com alguém que, entre si, trocam mensagens), das quais, em princípio, são excluídos terceiros.
\end{abstract}

O autor defende que a intimidade não experimenta qualquer forma de repercussão social, enquanto a vida privada envolve situações de opção pessoal que em alguns momentos podem requerer a comunicação a terceiros (como a escolha do regime de bens do casamento ou a outorga marital na aquisição de um imóvel).(FERRAZ JUNIOR, 2011, p. 79) Conceito que pode ser completado com a opinião do jurista René Ariel Dotti (1990, p. 69), no sentido de que "a intimidade envolve conceito mais restrito do que a vida privada. É mais intensa, daí sua natureza essencialmente espiritual (...).

Ferreira Filho (1999, p. 127) observa ainda que a intimidade é a vida em ambiente de convívio, no interior de um grupo fechado e reduzido, normalmente, ao grupo familiar. Apesar de estar-se diante de conceitos voláteis e dinâmicos o fato é que tanto a esfera privada quanto a intimidade da pessoa humana devem ser tutelados de toda a sorte de afrontas. As novas tecnologias propiciam o avanço a tais esferas com extrema facilidade, o que serve de estímulo aos infratores para saciarem suas curiosidades fúteis e mórbidas.

Proteger a privacidade e a intimidade da pessoa humana é em última análise reconhecer sua dignidade nata, propiciando seu desenvolvimento sem interferências externas desnecessárias e improdutivas. O indivíduo é mais do que um ser de carne e osso, a dignidade não se refere exclusivamente a sua vida e integridade física, mas também a toda a sua existência, a todas as suas potencialidades.

\title{
4 AS NOVAS FORMAS DE COMUNICAÇÃO E A PRIVACIDADE HUMANA
}


O mais importante da tecnologia é como ela muda as pessoas. (LANIER, 2012, p. 18) E as tecnologias atuais tornaram obsoletos os meios naturais de comunicação, ou seja, para se comunicar atualmente é necessário todo um aparato tecnológico. O ser humano se encontra num estágio de dependência do uso de redes virtuais e aparelhos de comunicação que a forma como nascemos já não é suficiente para uma existência social plena. Ninguém se imagina sem seus aparelhos celulares, tablets, computadores portáteis, que tornaram-se mais do que meros acessórios. Viraram instrumentos que são, em última análise, parte deste novo homem, que transcende seu corpo físico, renascendo como um ser virtual.

A evolução tecnológica criou ferramentas que, ao mesmo tempo em que facilitou o acesso à informação, também oportunizou o ingresso a fatos privados do ser humano. Segundo Alexandre Freire (2006, p. 24), atualmente está-se em construção um admirável mundo novo, em que o preço que se paga pela segurança é a própria liberdade. Essas ferramentas e os indivíduos podem vir a se tornar um só (CASTELLS, 1999, p. 69), representados apenas por uma imagem. Um avatar. E as interações entre as pessoas estão se tornando cada vez mais uma interação entre imagens na tela (CLELAND, 2008, p. 297), ou avatares.

Ao contrário do que se imagina, o avanço à privacidade do indivíduo não ocorre primeiramente por câmeras instaladas nas ruas, lojas, shoppings, aeroportos, dentre tantos espaços públicos, uma vez que a pessoa tem sua privacidade invadida dentro do útero materno, que, por meio de um aparelho de ultrassom, possibilita invadir o asilo mais seguro e recolhido do indivíduo (FREIRE, 2006, p. 24), o ventre materno, antes mesmo de estar completo e preparado para enfrentar a vida extra uterina. Há, portanto, o nascimento de problemas inéditos e desafios extremamente complexos quando a informação assume a forma de dado pessoal e sai totalmente do controle do seu titular. É a chamada virtualização da informação, que criou um novo tipo de saber-poder, que já está mudando paradigmas, sacudindo ideias e valores (SIBILIA, 2002, p. 13) e levando à desterritorialização da informação, por intermédio dos meios digitais cada vez mais sofisticados, que culminam na transformação da individualidade do sujeito em relação à coletividade (LEVY, 2011, p. 21).

O fato é que, de acordo com Alexandre Freire (2006, p. 24), “entre o nascimento e a morte, período que teoricamente ter-se-ia o controle do que se deseja expor ou ocultar, tornouse cada vez mais difícil manter os direitos de privacidade." Ainda segundo o autor, o progresso e a tecnologia cada vez mais barata e acessível a todos em qualquer canto do planeta, possibilita a crescente armazenagem e manipulação de dados por meio da internet. Assim, prevê, por fim, que não se está distante de um futuro em que a palavra privacidade perderá fôlego e importância, posto que tudo passará a ser público (FREIRE, 2006, p. 26). 
Os relacionamentos, cada vez mais, são mediados eletronicamente, submetendo informações pessoais a um número desconhecido de servidores de internet, tanto postagens em fóruns digitais ou redes sociais ${ }^{1}$, quanto pesquisas efetuadas em páginas de buscas são recolhidas pelo fornecedor (MORI, 2010, p. 68) e passam a fazer parte de bancos de dados que são utilizados para direcionar propaganda ou qualquer outro tipo de conteúdo que será enviado para o internauta sem qualquer solicitação.

Apesar da facilidade de acesso a conteúdos particulares, há de se resguardar a proteção aos fatos concernentes à vida privada, que encontra o seguinte significado na lição de Silvio Romero Beltrão (2005, p. 129):

\begin{abstract}
A definição do conteúdo e a dimensão do direito à vida privada tem início a partir do estudo dos fenômenos sociopsíquicos, em que os valores vigentes em cada época e lugar exercem influência sobre o indivíduo, que em razão desses valores tem a necessidade de resguardar do conhecimento de outras pessoas os aspectos mais particulares de sua vida.
\end{abstract}

A utilização de redes de comunicação é um processo indetível, uma vez que as funções e os processos dominantes na era da informação estão cada vez mais organizados em torno de redes, (CASTELLS, 1999, p. 565) dando origem à cibercultura:

[...] conjunto de técnicas (materiais e intelectuais), de práticas, de atitudes, de modos de pensamento e de valores que se desenvolvem juntamente com o ciberespaço, este o novo meio de comunicação que surge da interconexão mundial dos computadores. (LÉVY, 1999, p. 17)

A dignidade da pessoa humana é o fundamento primeiro e último do Direito, e o pressuposto axiológico que confere unidade ao ordenamento jurídico. Por ser um valor intrínseco, incondicional, universal, válido para toda e qualquer ação moral, a dignidade humana é imperativo categórico que assegura ao homem seu tratamento como um fim em si mesmo, e não como um meio a ser usado de forma arbitrária pela vontade dos outros.

Observa-se que a necessidade em proteger juridicamente o cidadão resulta do fato de que os dados pessoais adquiriram nos últimos anos forte componente econômico devido à possibilidade de sua comercialização, o que atrai empresas e fornecedores que atuam no ambiente virtual a utilizarem as mais variadas estratégias para obter dados dos internautas. Com efeito, os dados pessoais de um consumidor traduzem aspectos de sua personalidade e revelam comportamentos e preferências, tornando-o um alvo fácil de mensagens publicitárias em um mundo que ainda carece de transparência (LUDLOW, 2010, p. 234).

Quando se trata da Internet o tema ganha ainda mais interesse tendo em vista a 
possibilidade de criação de perfis psicológicos que revelam os hábitos de consumo, os gostos e

\footnotetext{
${ }^{1}$ Pode-se definir redes sociais como grupos ou espaços virtuais, que permitem partilhar dados e informações, sendo estas de caráter geral ou específico, das mais diversas formas (textos, arquivos, imagens fotos, vídeos, etc.).
}

preferências do indivíduo e, uma vez formado o perfil, posteriormente esse consumidor passa a ser alvo de publicidades indesejadas, $e$-mails que oferecem serviços, produtos e uma série de outras "promoções" que parecem elaboradas e direcionadas especialmente a ele, tudo articulado com base nos dados antes recolhidos. Percebe-se, pois, que as novas tecnologias informacionais, especialmente a Internet, convertem a informação em uma riqueza fundamental da sociedade, o que acentua a necessidade de sua proteção não só nas fronteiras territoriais de um país (COUTO, 2012, p. 186).

Por meio dessa nova perspectiva busca-se conferir maior poder e controle do titular sobre seus dados, na tentativa de conciliar o uso da Internet com níveis compatíveis de proteção a direitos fundamentais, como a intimidade e a privacidade. Trata-se, em outras palavras, de compreender que embora o ciberespaço historicamente tenha sido identificado como um ambiente propício para o exercício das liberdades, essa liberdade não é absoluta e toda a vez que o particular (pessoa física ou empresa) ou o próprio Estado expuserem dados pessoais de outros devem ser responsabilizados por eventuais danos causados ao titular. A pessoa teria, nesse sentido, com base no direito à intimidade, um poder de controlar a obtenção e o uso de suas informações pessoais por terceiros. Essa constatação encontra apoio em grande parte da doutrina que, segundo José Adércio Leite Sampaio (1998. p. 374-375), existem dois modos de violação da intimidade, quais sejam: o conhecimento e a difusão de fatos privados.

Capelo Souza (1995, P. 370) vai mais adiante, estabelecendo diversas condutas como infração à esfera privada:

Tais modos de violação da esfera privada podem abranger vários níveis de intersecção com os bens tutelados, desde o simples espiar de assuntos privados ou o mero documentar, v. g. por gravação, fotografia ou por meio informático, de circunstâncias do ser particular e da vida privada de outrem (...).

Ou ainda, "[...] violação de propriedade, violações da confiança, violações do direito do autor e também dos casos de difamação" (Linberger, 2007, p. 55), muito comuns no ambiente online, dada a possibilidade do anonimato. Na ótica de Milton Fernandes (1977, P. 80), as ingerências passíveis de refletirem ofensa ao direito à intimidade e privacidade podem ser relacionadas: 
a) interferência na vida privada pessoal, familiar e doméstica; b) interferências na integridade física ou mental, na liberdade moral e intelectual; c) violação da honra e reputação; d) falsa perspectiva; e) comunicação de fatos irrelevantes e embaraçosos da intimidade; f) uso do nome, identidade ou retrato; g) espionagem ou espreita; h) intervenção de correspondência; i) má- utilização de informações escritas ou orais; e j) transmissão de dados conhecidos em função do segredo profissional.

Em relação à internet, uma faceta dos direitos de intimidade e privacidade está contida nos dados digitais que trafegam pela rede, que fazem parte da esfera privada de cada um. E que tipo de dados ou informações, quando divulgados podem levar às lesões? São, portanto, quaisquer informações de qualquer natureza e independentemente do respectivo suporte, incluindo som e imagem, relativas a uma pessoa física identificada ou identificável (DRUMMOND, 2003, p. 125).

Mesmo na impossibilidade de se estabelecer um conceito único acerca de qual tipo de dado virtual enquadra-se dentro da esfera privada, é necessária a intervenção do legislador, na criação de normas que possam resguardar os direitos de personalidade.

O papel do Direito e a consecução da Justiça entre os homens, fator fundamental do convívio social e a realização do individual e comum, pouco importando que as relações ocorram por meio de uma ferramenta tecnológica que pareça separada da realidade. O que interessa é que as consequências são sentidas no mundo real - e precisam de uma resposta eficiente. (LEONARDI, 2002, p. 42)

É razoável que haja a exploração dos dados do usuário como forma de manutenção dos serviços gratuitos. Custear um servidor, armazenar e-mails, fornecer uma série de produtos é dispendioso ao proprietário do website. Ao mesmo tempo, o serviço interessa ao internauta. Ora, o que seria da Internet se não houvesse possibilidade de usar um serviço gratuito de pesquisas de websites? Seria necessário pagar por um site que faça isso. Portanto, existe negócio jurídico, cuja remuneração não é por pagamento em espécie, mas por exploração econômica dos dados do internauta. E esta exploração, à luz do que é balizado pela doutrina, pode vir a ser razoável e aceitável, por ser restrição voluntária ao direito da personalidade, desde que o website cumpra com a boa-fé, restringindo-se a tão-somente repassar os dados que sejam elementares para a publicidade, sendo que qualquer abuso pode ser punido, por tutela decorrente de violação do direito da personalidade e o critério para balizar o limite do repasse dos dados pode ser tanto os termos de uso (que em geral preveem os limites da exploração) quanto o razoável, em sede de cláusula geral, ensejando ação de responsabilidade civil (EVANGELISTA, 2013, p.1227).

De outro lado, se não considerar a relação como sendo negocial, de igual modo, o direito da personalidade é cláusula geral de tutela da pessoa humana, sendo que a violação da 
privacidade, que é atributo do direito da personalidade, pode ser tutelada em sede de tutela reparatória de lesão ao direito da personalidade.

\section{LEGISLAÇÃO ATINENTE AO MUNDO VIRTUAL}

A legislação que regula direitos e deveres na internet ainda não é considerada suficiente para salvaguardar com clareza todos os direitos daquele que navega no mundo virtual, notadamente aqueles relativos à personalidade.

Essa dificuldade vem do fato de que entre os usuários da internet há uma mescla heterogênea de perfis e interesses dificilmente classificáveis e este desconhecimento levou as pessoas a assistirem a popularização da internet sem poder explicar efetivamente os valores propulsores da mesma (LAGARES, 2013, p. 52/53). Ao passo que existe a possibilidade de ser apenas um anônimo na internet, a mesma rede promove a interligação virtual entre milhões de pessoas mundo afora. A informação que antes necessitava ser impressa e transportada sob a forma de livros, revistas e jornais está em via de se transformar totalmente na transferência instantânea e barata de dados eletrônicos movendo-se à velocidade da luz (NEGROPONTE, 1995, p. 10).

Tais fatores resultam na noção concreta do quão difícil é legislar acerca de interesses tão diversos e em um campo que transformou a própria maneira humana de se comunicar e transmitir informações. Preservar a individualidade do internauta ao mesmo tempo em que se assegura o direito à liberdade de expressão acarreta em um acúmulo de possibilidades e interesses heterogêneos tão diversos que os recentes estudos não conseguem revelar com clareza ao ponto de se conceber uma legislação ampla e completa para assegurar todos os direitos no mundo virtual. (LAGARES, 2013, p. 53) Tem-se demonstrado particularmente delicada a operação para delimitar a esfera da privacidade, mas é evidente que o direito à privacidade constitui um limite natural ao direito à informação (PAESANI, 208, p. 33).

Limitar a própria intimidade e privacidade é direito pessoal de cada um, mas a internet já comprovou ser um local impossível de ser dominado por completo. A informação disponibilizada na rede virtual pode tornar-se incontrolável e fugir totalmente da área que inicialmente foi prevista como alvo para uma publicação, ainda mais considerando-se a característica supranacional da internet e a velocidade com que as informações são disseminadas. Uma informação postada na internet pode ser lida simultaneamente em qualquer 
ponto do mundo e alguns segundos depois pode ser comentada e compartilhada por vários usuários, multiplicando-a em escala geométrica (DOMINGUES, 2010, p. 55).

A forma encontrada para criar mecanismos jurídicos que pudessem servir de proteção para os usuários da internet foi estabelecer a proteção dos dados pessoais. Com isto transformase todo tipo de informação (postagens, documentos, fotos, vídeos, arquivos de som) em dados, que são o conjunto de códigos matemáticos que formam as informações. A proteção dos dado pessoais é de suma importância para a defesa dos direitos individuais (TORTAJADA, 2013, p. $73)$.

Tanto a Lei Carolina Dieckman ${ }^{2}$ quanto o Marco Civil ${ }^{3}$ são considerados avanços na tentativa de organizar juridicamente o espaço virtual, apesar de a primeira ter sido promulgada com a desnecessária urgência que a discussão da matéria requer e a segunda não ter tratado de temas relevantes, como o cyberbulling ${ }^{4}$ e a ação de ação de hackers $^{5}$ e crackers $^{6}$.

A criação de ambas as leis demonstra a preocupação do ordenamento jurídico brasileiro em proteger os direitos pessoais, notadamente aqueles relativos à intimidade e privacidade, no âmbito das relações virtuais, onde o espaço cibernético destrói severamente a relação entre a legislação e a localização física do usuário da rede, que pode sofrer ofensa em seu direito partindo de qualquer lugar do mundo, eis que ingressa-se em um lugar em que não há mais limites, não há mais tempo e nem horários (SILVA NETO, 2001. p. 33).

A estória hoje é contada em bytes (PEREIRA; GHEZZI; VESNIC-ALUJEVIC, 2014, p. 17) e os mais variados bancos de dados encontram-se disponíveis na internet, ao alcance quase que ilimitado de uma grande parte da humanidade. Se antes a informação repousava no papel em vez de reverberarem nas telas de computadores, na forma de dados virtuais a privacidade ainda podia se sustentar. Após a internet se tornar o maior arquivo de dados jamais concebido pela humanidade, o direito à privacidade se dissolve (SILVA NETO, 201, p. 33).

\footnotetext{
2 A Lei 12.737/2012, sancionada em 3 de dezembro de 2012, promoveu alterações no Código Penal Brasileiro, tipificando os chamados delitos ou crimes cibernéticos. Acrescentou ao Código Penal os artigos 154-A a 154B, situados dentro dos crimes contra a liberdade individual, prevendo pena de três meses a um ano de detenção para aquele que "Invadir dispositivo informático alheio, conectado ou não à rede de computadores, mediante violação indevida de mecanismo de segurança e com o fim de obter, adulterar ou destruir dados ou informações sem autorização expressa ou tácita do titular do dispositivo ou instalar vulnerabilidades para obter vantagem ilícita". A lei resultou de uma situação experimentada pela atriz que batizou o normativo, onde teve copiadas de seu computador pessoal 36 (trinta e seis) fotos em situação íntima, que acabaram divulgadas na Internet, após tentativa frustrada de receber dinheiro pela não publicação por parte daquele que cometeu o delito.

${ }^{3}$ A Lei no 12.965 , sancionada em 23 de abril de 2014 é a lei que regula o uso da Internet no Brasil, prevendo os princípios, garantias, direitos e deveres para quem usa a rede, bem como da determinação de diretrizes para a atuação do Estado. A lei trata de temas como neutralidade da rede, privacidade, retenção de dados, a função social
} 
que a rede precisará cumprir, especialmente garantir a liberdade de expressão e a transmissão de conhecimento, além de impor obrigações de responsabilidade civil aos usuários e provedores de internet.

$4 \mathrm{O}$ cyberbulling pode ser entendido como uma forma de violência praticada através das tecnologias de comunicação e informação e que consiste em uma agressão, normalmente de ordem moral e cunho psicológico, com a publicação de informações que visam denegrir a imagem e afetar a autoestima da vítima. Pode ser feita por uma pessoa ou um grupo que se une para praticar as agressões. O abuso é constante e impossível de se controlar, pois a própria natureza da internet, com conexões ilimitadas, sem fronteiras definidas e possibilidade de postagens anônimas, torna inviável a defesa desse tipo de agressão, onde há casos extremos de suicídio por parte dos ofendidos.

${ }^{5}$ Indivíduos que se dedicam, com intensidade e conhecimentos em informática incomuns, a invadir e modificar os aspectos mais internos de dispositivos, programas e redes de computadores, tendo acesso a dados privados de suas vítimas. Os ataques são feitos pela internet e o criminoso obtém acesso quase irrestrito ao computador da vítima.

6 Também possuem profundos conhecimentos em informática, que utilizam para fins imorais, ilegais ou prejudiciais, normalmente motivados por curiosidade, necessidade profissional, vaidade, espírito competitivo, patriotismo, ativismo ou simplesmente para cometer crimes cibernéticos.

A criação de uma constituição da internet, como foi chamado o Marco Civil constituise em importante passo para a proteção ao direito à intimidade e privacidade dos internautas e constitui-se em singela barreira contra a violação de direitos no âmbito virtual e instrumento de proteção de dados e informações pessoais, considerando-se o fato de que o acesso ilimitado ao conteúdo indexado virtualmente não poupa absolutamente ninguém (VIEIRA, 2002, p. 70).

A lei 12.965 (BRASIL, 2014) colocou no artigo terceiro, como um dos princípios que disciplinam o uso da internet, a proteção da privacidade e no artigo sétimo o direito à inviolabilidade tanto da vida privada quanto da intimidade. No entanto, em razão da extrema competição entre as empresas que produzem conteúdo virtual, a cada dia são lançados novos aplicativos e criadas ferramentas e ambientes virtuais para seduzir um público que não cessa de crescer. E, encantados pelas novas oportunidades de interconexão, os internautas revelam-se assíduos utilizadores de sites de redes sociais, nos quais disponibilizam e divulgam voluntariamente suas informações pessoais, sem se preocupar com quem irá acessá-las ou para qual finalidade serão utilizadas.

O Marco Civil brasileiro erigiu, dentre outros, os princípios da garantia da liberdade de expressão, comunicação e manifestação do pensamento, a proteção da privacidade e a proteção dos dados pessoais ao mesmo passo em que elegeu, como fundamento do uso da internet, os direitos humanos e o desenvolvimento da personalidade. Entretanto, o avanço da comunicação digital se dá em escala geométrica, alcançando um número cada vez maior de pessoas em um espaço de tempo cada vez mais curto, com o surgimento de novas plataformas e canais de comunicação, com o qual o usuário se vê cada vez mais exposto (MARTíNEZ, 2016, p. 161).

É louvável a criação de normas específicas para a proteção dos direitos dos internautas, principalmente aqueles relativos à honra, intimidade e privacidade, que, em última análise, encontram-se vinculados à própria defesa do princípio da dignidade humana, mas também é 
necessário aperfeiçoar as ferramentas existentes para se conter a erosão em tais direitos fundamentais.

\section{CONCLUSÃO}

A internet é uma das inovações tecnológicas que assumiu, nos últimos tempos, maior importância na sociedade, muito em virtude da agilidade e rapidez no trânsito de dados e na comunicação interpessoal, o que tem atraído cada vez mais usuários. O aumento no número de usuários é diretamente proporcional ao aumento na complexidade das relações tidas no campo cibernético, sendo possível encontrar tanto conexões afetivas e sociais quanto comerciais, que se desenrolam exclusivamente no campo virtual.

Essas novas formas de informação e comunicação geram uma quantidade imensa de dados virtuais, que carregam referências pessoais daqueles que transitam no mundo virtual e que pertencem aos proprietários dos espaços utilizados pelos internautas, sendo utilizados para fins comerciais à revelia dos usuários.

Além do trânsito de informações desprovido do mínimo de transparência, constata-se a possibilidade da utilização das ferramentas virtuais na busca de autopromoção pessoal, centrada na fama, no prestígio e popularidade suficiente para alçar a pessoa comum ao nível de celebridade.

A rede, indubitavelmente, apresenta-se como um novo instrumento de comunicação social, eficaz, de fácil acesso e de baixo custo. Todos esses atrativos aliados a questões de ordem moral, cultural e psicológicas, servem de incentivo às pessoas para que desnudem suas vidas, narrando os seus passos e expondo suas intimidades, num conto do cotidiano, fútil e fugaz.

O indivíduo foge da existência real, de contatos pessoais e íntimos, para viver uma existência virtual, abrindo sua vida e descortinando seus dados, na intenção de atingir aprovação e reconhecimento, sacrificando sua intimidade e privacidade. A vida passou a ser encenada para um número inestimável de telespectadores, como uma novela a ser seguida e compartilhada. As informações disponíveis na rede tornam-se perenes, pois a internet não esquece. Assim não se concede ao usuário a benesse do recolhimento, uma vez que basta apenas um clique para que os dados e fatos relativos a sua existência sejam acessados de forma instantânea.

A criação de leis específicas acerca da utilização do espaço virtual é sinal de avanço do legislador nesse campo. Estabelecer os princípios legais que irão servir de norte para a legislação, como fez o Marco Civil, já estabelece o entendimento das bases sobre o qual irá se assentar a resolução dos conflitos oriundos do mundo virtual. 
O Direito preocupou-se em disciplinar o uso das novas tecnologias, em especial a internet, protegendo o indivíduo dos ataques que possa sofrer de outros indivíduos reais ou virtuais, todavia, como proteger as pessoas de si mesmas quando expõem sua intimidade e privacidade na busca de fama e aceitação através da espetacularização da sua própria vida?

O Direito ao longo da história foi invocado para tutelar a pessoa humana dos ataques e afrontas cometidos pelo Estado ou pelo próprio homem, e agora, vê-se desafiado a proteger o indivíduo de si mesmo, quando este se despe de sua dignidade voluntariamente, coisificando sua existência, abrindo mão de seus direitos mais íntimos e pessoais.

\section{REFERENCIAS}

ARANGY, Lidia Rosenberg. Adolescentes na era digital. São Paulo: Benvirá, 2011.

BELTRÃO, Silvio Romero. Direitos da personalidade: de acordo com o novo código civil. São Paulo: Atlas. 2005.

BRASIL. Lei n ${ }^{\circ}$ 12.965, de 23 de abril de 2014. Marco Civil. In: Diário Oficial da República Federativa do Brasil, Brasília, DF, 24 abr. 2014. Disponível em: $<$ http://www.planalto.gov.br/ccivil_03 /_ato2011-2014/2014/lei/112965.htm>. Acesso em: 23 de julho de 2015

CASTELLS, Manuel. Tradução: Roneide Venâncio Majer; A sociedade em rede. São Paulo: Editora Paz e Terra S/A, 1999.

CASTRONOVA, Edward. Synthetic Worlds: the business and culture of online games. Chicago: The University of Chicago Press, 2005. [Ebook]

CLELAND, Kathy. Image Avatars: Self-Other Encounters in a mediated word. Sidney: University of Technology, 2008.

COUTO, Thiago Graça. O Direito virtual. 2012 [Ebook]

DONEDA, Danilo. Reflexões sobre proteção de dados pessoais em redes sociais. Disponível em

https://www.academia.edu/5230146/Reflex\%C3\%B5es_sobre_prote\%C3\%A7\%C3\%A3o_de _dados_em_redes_sociais. Pg. 6. Acessado em 22/05/2015

DOMINGUES, David Calcevilla. Las redes sociales. Tipologia, uso y consumo de las redes 2.0 em la sociedade digital actual. Madrid: Documentación de las Ciencias de la Información, 2010.

DOTTI, René Ariel. Proteção da vida privada e liberdade de informação. São Paulo: RT, 1990. 
DRUMMOND. Victor. Internet privacidade e dados pessoais. Rio de Janeiro: Lumen Juris, 2003.

EVANGELISTA, Marco. InfoDireito em 16 aulas. Manaus: ArkiUltra, 2013. [Ebook]

FARIAS, Edilsom Pereira de Farias. Colisão de direitos: a honra, a intimidade, a vida privada e a imagem versus a liberdade de expressão e informação. $2^{\mathrm{a}}$. ed. Atual. Sergio Antonio Fabris Editor: Porto Alegre, 2000.

FERNANDES, Milton. Proteção civil da intimidade. São Paulo: Saraiva, 1977.

FERRAZ JUNIOR. Tercio Sampaio. O direito, entre o futuro e o passado. São Paulo: Noeses, 2014.

FERREIRA FILHO, Manoel Gonçalves. Direitos humanos fundamentais. São Paulo: Saraiva, 1999.

FREIRE, Alexandre. Inevitável mundo novo: o fim da privacidade. São Paulo: Axis Mundi, 2006.

JABUR, Gilberto Haddad. Liberdade de pensamento e direito à vida privada: conflitos entre direitos da personalidade. São Paulo: Editora Revista dos Tribunais, 2000.

LAGARES, Diego. Internet y el Derecho. Barcelona: Ediciones Carena.

LANIER, Jaron. Bem-vindo ao futuro: uma visão humanista sobre o avanço da tecnologia. São Paulo: Saraiva, 2012.

LEANDRY-VEGA, Ismael. Usted no tiene privacidade. North Charleston, Editorial Espacio Creativo, 2014.

LEONARDI, Marcel. Tutela e privacidade na internet. São Paulo: Saraiva, 2012.

LEVY, Benito Javier Gutiérrez. La dignidade de la persona humana em el mundo virtual. Saarbrucken: Editorial Académia Española, 2011.

LÉVY, Pierre. Cibercultura. São Paulo: Editora 34, 1999.

LEVY, Pierre. O que é o virtual? Tradução de Paulo Neves. São Paulo: Editora 34, 2011.

LIMBERGER, Têmis. O direito à intimidade na era da informática: a necessidade de proteção dos dados pessoais. Porto Alegre: Livraria do Advogado, 2007.

LUDLOW, Peter. Nosso futuro nos mundos virtuais. Milano: DigitPub srl 2010. [Ebook]

MARTÍNEZ, Silvia. El derecho a la intimidad en el periodismo participativo. In: GARDÓ, Antonio Fayos. Los derechos a la intimidad y la privacidad en el siglo XXI. Madrid: Dykinson, 2013. 
MORI, Michele Keiko. Direito à intimidade versus informática. Curitiba: Jurá, 2010. p. 68.

NEGROPONTE, NICHOLAS. A vida digital. São Paulo: Companhia das Letras, 1995.

NUNES, Luiz Antônio Rizzatto. O princípio constitucional da dignidade da pessoa humana: doutrina e jurisprudência. São Paulo: Saraiva, 2002.

PAESANI, Liliana Minardi. Direito e internet: liberdade de informação, privacidade e responsabilidade civil. São Paulo: Atlas, 2008.

PEREIRA, Ângela Guimarães; GHEZZI, Alessia, and VESNIC-ALUJEVIC, Lucia. The Ethics of Memory in a Digital Age: Interrogating the Right to be Forgotten. New York: Palgrave Macmillan Memory Studies, 2014 [Ebook]

SARLET, Ingo Wolfgang. Dignidade da pessoa humana e direitos fundamentais na Constituição Federal de 1988. Porto Alegre: Livraria do Advogado, 2001.

SAMPAIO, José Adércio Leite. Direito à intimidade e à vida privada: uma visão jurídica da sexualidade da família, da comunicação e informações pessoais, da vida e da morte. Belo Horizonte: Del Rey, 1998.

SIBILIA, Paula. O homem pós-orgânico: corpo, subjetividade e tecnologias digitais. Rio de Janeiro: Relume Dumará, 2002.

SIBILIA, Paula. O show do eu: a intimidade como espetáculo. Rio de Janeiro: Nova Fronteira, 2008.

SILVA NETO, Amaro Moraes e. Privacidade na internet: um enfoque jurídico. Bauru: Edipro, 2001.

SOUZA. Rabindranath V. A. Capelo. O direito geral de personalidade. Coimbra: Coimbra Editora, 1995.

SZANIAWSKI, Elimar. Direitos de personalidade e sua tutela. $2^{\mathrm{a}}$. ed. rev. atual. e ampl. São Paulo: Editora Revista dos Tribunais, 2005.

TOMASZEWSKI, Adalto de Almeida. Direitos da personalidade - abordagens constitucionais, civis e processuais. Londrina: Midiograf. 2006.

TORTAJADA, Patricia Escribano. Algunas cuestiones sobre la problemática juridica del derecho a la intimidad, al honor y a la propia imagen en internet y en las redes sociales. In: GARDÓ, Antonio Fayos. Los derechos a la intimidad y la privacidad en el siglo XXI. Madrid: Dykinson, 2013.

VAZ, Wanderson Lago; REIS, Clayton. Dignidade da pessoa humana. Revista Jurídica Cesumar - Mestrado. V. 7. Maringá: UNICESUMAR, 2007.

Disponível em file:///C:/Users/SAMSUNG/Downloads/522-1435-1-PB\%20(1).pdf . Acesso em 10 de Agosto de 2015.

VIEIRA, Sônia Aguiar do Amaral. Inviolabilidade da vida privada e da intimidade pelos meios eletrônicos. São Paulo: Editora Juarez de Oliveira. 2002. 
VIEIRA, Tatiana Malta. $\mathbf{O}$ direito à privacidade na sociedade da informação: efetividade desse direito fundamental diante dos avanços da tecnologia da informação. 2007. 297 f. Dissertação (Mestrado) - Curso de Mestrado em Direito, Estado e Sociedade, Universidade de Brasília, Brasília, 2007. Disponível em: <http://repositorio.unb.br/bitstream/10482/3358/1/2007_TatianaMaltaVieira.pdf>. Acesso em: 4 ago. 2015. 